\title{
Antisense Oligonucleotide: Basic Concepts and Therapeutic Application in Inflammatory Bowel Disease
}

\section{OPEN ACCESS}

Edited by:

Ruixin Zhu,

Tongji University, China

Reviewed by:

Zhanju Liu,

Tongji University, China Jose A. Uranga,

Universidad Rey Juan Carlos, Spain

Anthony C. Johnson,

Oklahoma City VA Health

Care System, United States

Oksana Zayachkivska,

Danylo Halytsky Lviv National

Medical University, Ukraine

${ }^{*}$ Correspondence:

Davide Di Fusco

davidedifusco@gmail.com

tThese authors have contributed equally to this work

Specialty section: This article was submitted to Gastrointestinal and Hepatic Pharmacology,

a section of the journal Frontiers in Pharmacology

Received: 03 December 2018 Accepted: 12 March 2019 Published: 29 March 2019

Citation:

Di Fusco D, Dinallo V, Marafini I, Figliuzzi MM, Romano $B$ and Monteleone G (2019) Antisense Oligonucleotide: Basic Concepts and

Therapeutic Application in Inflammatory Bowel Disease.

Front. Pharmacol. 10:305.

doi: 10.3389/fphar.2019.00305

\section{Davide Di Fusco ${ }^{1 \star}$, Vincenzo Dinallo ${ }^{1 \dagger}$, Irene Marafini', Michele M. Figliuzzi', Barbara Romano ${ }^{2}$ and Giovanni Monteleone ${ }^{1}$}

'Department of Systems Medicine, Gastroenterology, University of Tor Vergata, Rome, Italy, 'Department of Pharmacy, School of Medicine and Surgery, University of Naples "Federico II", Naples, Italy

Several molecular technologies aimed at regulating gene expression that have been recently developed as a strategy to combat inflammatory and neoplastic diseases. Among these, antisense technology is a specific, rapid, and potentially high-throughput approach for inhibiting gene expression through recognition of cellular RNAs. Advances in the understanding of the molecular mechanisms that drive tissue damage in different inflammatory diseases, including Crohn's disease (CD) and ulcerative colitis (UC), the two major inflammatory bowel diseases (IBDs) in humans, have facilitated the identification of novel druggable targets and offered interesting therapeutic perspectives for the treatment of patients. This short review provides a comprehensive understanding of the basic concepts underlying the mechanism of action of the oligonucleotide therapeutics, and summarizes the available pre-clinical and clinical data for oligonucleotide-based therapy in IBD.

Keywords: inflammatory bowel disease, ulcerative colitis, Crohn's disease, antisense oligonucleotide, RNA interference

\section{INTRODUCTION}

The central dogma of molecular biology states that DNA encodes RNA, which is then translated into proteins. In recent years, the use of compounds that are able to bind messenger RNAs (mRNAs) has gained increasing interest as inhibition of protein expression can be helpful for controlling the course of inflammatory and neoplastic diseases. The two major therapeutic approaches in this field are the antisense oligonucleotides (ASOs) that inhibit mRNA translation and the oligonucleotides, which function via RNA interference (RNAi) pathway (Chan et al., 2006; Chery, 2016). Synthetic oligonucleotides are negatively charged molecules with different chemical properties based on the technology used for their design. In order to regulate target gene expression, these compounds have to reach disease-associated tissues and cross cell membranes. This is in part facilitated by the manipulation of their chemical structure, which makes oligonucleotides also more powerful and less toxic with a lower chance to have off-target effects and to activate the host immune system (Sharma and Watts, 2015). 
In the last decades, the advent of new techniques of molecular and cellular biology has advanced our understanding of the factors/mechanisms that promote tissue damage in several chronic inflammatory diseases, including Crohn's disease (CD) and ulcerative colitis (UC), the two major inflammatory bowel diseases (IBDs) in humans (Neurath, 2017). This has contributed in identifying novel druggable targets, thus offering interesting therapeutic perspectives for the treatment of these patients. We here shortly review the basic concepts underlying the mechanism of action of the ASOs and summarize the available data for ASO-based therapy in IBD.

\section{ANTISENSE OLIGONUCLEOTIDE STRATEGY AND MOLECULE DESIGN}

An antisense oligonucleotide (ASO) is a single-stranded deoxyribonucleotide, which is complementary to the mRNA target. The goal of the antisense approach is the downregulation of a molecular target, usually achieved by induction of RNase $\mathrm{H}$ endonuclease activity that cleaves the RNA-DNA heteroduplex with a significant reduction of the target gene translation (Figure 1). Other ASO-driven mechanisms include inhibition of $5^{\prime}$ cap formation, alteration of splicing process (spliceswitching), and steric hindrance of ribosomal activity (Chan et al., 2006; Bennett et al., 2017; Crooke, 2017).
The recent developments in the human genome sequencing, the possibility of a rational design of oligonucleotides and the theoretical simplicity, and relatively cheap costs of these compounds led to their use as either therapeutic agents or tools for assessing gene function. Although, the researchers usually select the ASO candidate by testing the activity of few oligonucleotides that specifically regulate the target gene expression, it would be recommendable to identify the ideal ASO through an accurate evaluation of a panel of putative oligomers (Tu et al., 1998; Stein, 2001). It is crucial that the ASOs do not bind, even partially, to a nontarget mRNA. In this context, it is noteworthy that 6-7 base pairs between the ASO and nontarget mRNA are sufficient to initiate RNase activity, leading to cleavage of the wrong target. The secondary and tertiary structure of the RNA must be taken into account to minimize the possibility that the selected sequence is inaccessible to binding (Ho et al., 1998; Vickers et al., 2000; Andronescu et al., 2005). To this end, the use of software with a robust RNA folding program (e.g., Sfold or mfold) can help select the optimal candidate (Zuker, 2003; Ding et al., 2004). Generally, the length of an ASO is approximately 20 nucleotides and the ASO is selected to target either the methionine (AUG) initiation codon (to block translation) or splice sites (to block splicing) (Chan et al., 2006; Chery, 2016). The effective knockdown of the target is usually demonstrated at the protein level, but analysis of RNA expression should be made in order to exclude that the

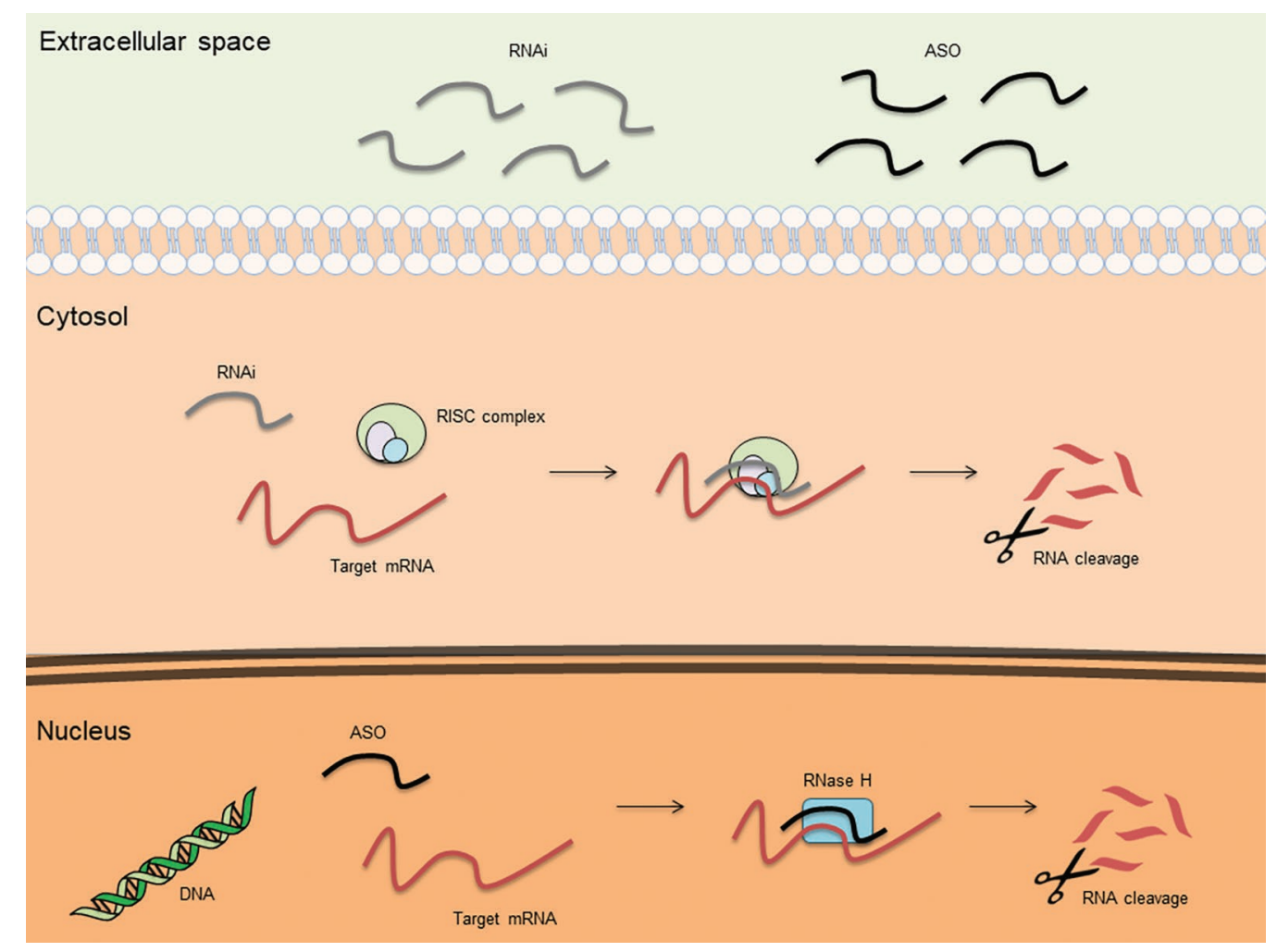

FIGURE 1 | Basic mechanisms of action for therapeutic antisense oligonucleotides (ASOs) and RNA interference (RNAi). 
target protein is down-regulated through a non-sequence specific mechanism. To maximize sequence specificity, ASOs should not be designed into polymorphic/mutated regions of the genome and selection should exclude oligonucleotides targeting four contiguous guanosine residues in order to avoid generation of tetraplexes via Hoogsteen base-pair formation (Sen and Gilbert, 1992; Benimetskaya et al., 1997; Crooke, 2004).

Since in their "naïve" form, ASOs could be rapidly digested, thus limiting their bioavailability (Eder et al., 1991), most of ASOs are phosphorothioated (Eckstein, 2014). This modification facilitates binding of ASOs to plasma proteins, thereby reducing their renal loss and improving uptake to several organs (e.g. liver, bone marrow, and lymph nodes). The chemical modification influences neither RNase $\mathrm{H}$ activity nor ASO solubility, thus allowing administration by different routes (e.g. subcutaneous, intravenous, topical, oral, or rectal). However, phosphorothioate oligonucleotides containing one or more CpG motifs can bind the Toll-like receptor (TLR) 9 and trigger innate immune responses. This issue can be overcome by either selecting oligonucleotides containing no CG or replacing the $\mathrm{C}$ with 5 methylC, which does not stimulate the immune system (Stein, 2001).

Increased ASO binding affinity and biostability have also been obtained using oligonucleotides with ribose modifications [i.e. substitution of the hydrogen at the 2-position by an O-alkyl group and locked nucleic acid technology (LNA)] that reduce conformational plasticity (Wahlestedt et al., 2000; Prakash, 2011; Hagedorn et al., 2018). However, LNA can accumulate in the liver and promote hepatotoxicity, mainly due to an off-target RNase $\mathrm{H}$ dependent RNA degradation (Burel et al., 2016).

ASOs have been already used in various human pathologies. For instance, in 1998, FDA approved the use of fomivirsen, a compound that inhibits the translation of the mRNA encoding for the major immediate early region proteins of cytomegalovirus, for the treatment of cytomegalovirus-induced retinitis (Jabs and Griffiths, 2002). In 2013, FDA approved the use of mipomersen, a compound targeting apolipoprotein B100, for the treatment of familial hypercholesterolemia (Duell et al., 2016), while later on, eteplirsen was introduced to treat Duchenne muscular dystrophy, and nusinersen was approved for spinal muscular atrophy treatment (Khorkova and Wahlestedt, 2017; Goyal and Narayanaswami, 2018). Eteplirsen binds to the disease-related-exon 51 of dystrophin RNA and allows the splicing of exon 52 to exon 51, thus generating a shortened but partly functional protein (exon skipping strategy) (Khorkova and Wahlestedt, 2017). Differently, nusinersen uses an exon switching strategy to increase the amount of functional full-length survival motor neuron-2 protein. After hybridization to its target, this oligonucleotide forces the inclusion of exon 7 into the mRNA and prevents the generation of short-lived/non-functional proteins (Goyal and Narayanaswami, 2018). Clinical trials employing ASOs in amyotrophic lateral sclerosis and familial amyloid polyneuropathy are also ongoing (Goyal and Narayanaswami, 2018).

\section{ANTISENSE OLIGONUCLEOTIDE-BASED THERAPIES FOR INFLAMMATORY BOWEL DISEASE}

\section{Alicaforsen: Intercellular Adhesion Molecule-1 Antisense Oligonucleotide}

IBD are chronic, immune-mediated diseases of the gastrointestinal tract, which are characterized by tissue damage and development of local and extra-intestinal lesions (Abraham and Cho, 2009; Neurath, 2017). One of the mechanisms sustaining the inflammatory process in IBD is the recruitment of immune cells from the peripheral blood to the intestine. Once activated in secondary lymphoid organs, such as Peyer's patches and isolated follicles, leukocytes enter the circulation, and through a process named gut homing, eventually go back to the intestinal wall. This process is triggered mainly by chemoattractants produced within the inflamed tissue and favored by interaction between integrins expressed on leukocyte surface and proteins expressed on endothelial cells, such members of immunoglobulin superfamily [i.e. intercellular adhesion molecule (ICAM)-1, ICAM-2, and vascular cell adhesion molecule (VCAM)-1] (Hart et al., 2010).

In inflamed gut of $\mathrm{CD}$ patients and UC patients, there is an enhanced expression of ICAM-1, a transmembrane glycoprotein constitutively expressed on the surface of intestinal epithelial cells and vascular endothelial cells (Vainer and Nielsen, 2000). Knockdown of ICAM-1 with specific ASO in mouse models of colitis reduced leukocyte trafficking to the gut and attenuated mucosal inflammation (Bennett et al., 1997). In a proof of concept study, Alicaforsen (ISIS 2302), a 20 base-long phosphorothioate ASO inhibiting ICAM1 production, was intravenously administered to 20 active CD patients for 26 days. The drug was well tolerated and superior to placebo in inducing clinical remission (Yacyshyn et al., 1998). However, steroiddependent or resistant CD patients treated with intravenous or subcutaneous alicaforsen in two subsequent clinical trials showed no clinical benefit (Schreiber et al., 2001; Yacyshyn et al., 2002). Similar negative results were also obtained in two subsequent placebo-controlled phase III trials, in which alicaforsen was given to moderate-to-severe active CD patients (Yacyshyn et al., 2007). Therefore, the therapeutic development of alicaforsen in $\mathrm{CD}$ was discontinued.

An alicaforsen-containing enema formulation was developed for patients with UC or patients with pouchitis, an inflammatory condition of the ileal pouch reservoir, which can develop in UC patients undergoing colectomy and ileal pouch-anal anastomosis. In mild to moderate left-sided UC patients, alicaforsen enema had no significant effect on the course of the disease (Miner et al., 2006; Van Deventer et al., 2006). Afterwards, a retrospective analysis evaluating the efficacy of alicaforsen enema (240 mg/day for 6 weeks) showed clinical benefits in patients with left-sided and distal UC and in patients with chronic pouchitis (Greuter et al., 2018). However, treatment was not sufficient to stably control the inflammation as more than $2 / 3$ of the patients relapsed within 16 weeks (Greuter et al., 2016). A phase III, multicenter, double-blind, placebo-controlled trial 
(NCT02525523) assessing the safety and efficacy of topical alicaforsen enema $(240 \mathrm{mg} /$ day for 6 weeks) has been recently completed in subjects with antibiotic refractory pouchitis but results are not yet available.

\section{NF-кB Antisense Oligonucleotide}

$\mathrm{NF}-\mathrm{kB}$ is a transcription factor composed of two proteins (p50 and p65) regulating the expression of many inflammatory and anti-inflammatory genes (Rogler et al., 1998; Schreiber et al., 1998). It was shown that either intravenous or intrarectal ASO targeting the p65 subunit of NF- $\mathrm{kB}$ inhibited production of inflammatory cytokines and signs of colitis induced in mice by trinitrobenzene sulfonic acid (TNBS) or IL-10 deficiency (Neurath et al., 1996). Consistently, the specific p65 ASO reduced production of inflammatory cytokines in macrophages and endothelial cells isolated from the gut of CD patients (Neurath et al., 1998). These data were in line with the demonstration that downregulation of NF- $\mathrm{kBp} 65$ with a specific ASO attenuated dextran sodium sulfate (DSS)-induced colitis (Murano et al., 2000) and intestinal fibrogenic processes in mice (Lawrance et al., 2003). Despite these encouraging data in IBD-like murine models, no data are currently available on the use of NF- $\mathrm{BB}$ ASO in IBD.

\section{Smad7 Antisense Oligonucleotide}

IBD is believed to be triggered by complex interactions among host genetic susceptibility and many environmental factors, which lead to a sustained activation of inflammatory pathways and defects in counter-regulatory mechanisms in the gut (Gorelik and Flavell, 2002; MacDonald et al., 2011). In intestinal immunity, transforming growth factor (TGF)- $\beta 1$, a pleiotropic cytokine produced by many cell types suppresses inflammatory responses to luminal antigens, thus contributing to immune tolerance induction. The anti-inflammatory mechanism of TGF- $\beta 1$ relies mainly on the intracellular phosphorylation and subsequent activation of TGF- $\beta 1$ receptor-associated Smad $2 / 3$ proteins (Heldin et al., 1997; Shi and Massague, 2003). In IBD patients, phosphorylated-Smad2/3 expression is reduced thus underlying the inability of TGF- $\beta 1$ to adequately control inflammatory signals (Babyatsky et al., 1996). Such a defect has been associated with increased levels of Smad7, a cytosolic protein that inhibits TGF- $\beta 1 /$ Smad-associated pathway (Monteleone et al., 2001; Sedda et al., 2015). Responsiveness of IBD mucosal cells to TGF- $\beta 1$ is restored by downregulation of Smad7 with a specific ASO (Monteleone et al., 2001). Oral administration of Smad7 ASO to mice with TNBS and oxazolone-induced colitis restores TGF- $\beta 1$-associated Smad signaling and mitigates intestinal inflammation (Boirivant et al., 2006).

Later on, a pharmaceutical compound, which contains a Smad7 ASO targeting the RNA encoding by the 107-128 DNA region, was developed for $\mathrm{CD}$ therapy. The drug, named mongersen (previously called GED-0301), (Monteleone et al., 2012; Laudisi et al., 2016), was formulated in order to maximize the active compound release into the lumen of the terminal ileum and right colon, the intestinal regions mainly involved in CD. A phase I clinical, open-label, dose-escalating study in patients with active, steroid-dependent/resistant CD showed that mongersen was safe and well-tolerated and treatment was associated with a clear clinical benefit (Monteleone et al., 2012). Although TGF- $\beta 1$ is known to be pro-fibrogenic (Leask and Abraham, 2004; Vallance et al., 2005), no patient recruited into the trial developed strictures (Zorzi et al., 2012). This later result was consistent with data generated in mice with TNBS-mediated colitis-driven intestinal fibrosis, in which knockdown of Smad7 with the specific ASO reduced intestinal inflammation and fibrosis (Izzo et al., 2018). A double blind, placebo controlled, phase II trial was conducted in 166 active, steroid-dependent/resistant $\mathrm{CD}$ patients (Monteleone et al., 2015). Patients were allocated to receive one of three doses of mongersen (10,40, or $160 \mathrm{mg}$ per day) or placebo daily for 2 weeks. Patients receiving the 40 and $160 \mathrm{mg}$ of mongersen reached significant higher rates of remission (55 and 65\%, respectively) than those treated with $10 \mathrm{mg}$ or placebo (12 and 10\%, respectively). At the end of follow-up, the percentage of patients who had a steroid-free remission was significantly greater in the $160-\mathrm{mg}$ group than in the placebo group. The study confirmed the safety profile of the drug (Monteleone et al., 2015). These data were confirmed by a subsequent multicenter, randomized study, which evaluated the effect of mongersen on endoscopic outcomes (Feagan et al., 2018). Sixty-three active CD patients were randomized (1:1:1) to 4,8 , or 12 weeks of oral mongersen (160 mg daily). Endoscopic improvement was observed in $37 \%$ of participants. All three mongersen regimens induced rapid, clinically meaningful decreases in Crohn's disease activity index scores. Moreover, reductions in high-sensitivity C-reactive protein levels and fecal calprotectin were observed in patients with increased values at baseline (Feagan et al., 2018). A phase III clinical trial has been recently suspended due to an interim analysis documenting the lack of efficacy of mongersen. The reasons for this unexpected result are still to be clarified.

\section{RNA INTERFERENCE STRATEGY AND ITS THERAPEUTIC APPLICATION}

Another strategy to inhibit the expression of mRNA is represented by RNAi. RNAi is mediated by many endogenous RNAs [e.g. piwi-interacting RNA (piRNA), microRNA (miRNA), and small interfering RNA (siRNA) (Li and Rana, 2012)]. Once incorporated into the RNA-induced silencing complex (RISC), these RNAs cause translational repression/degradation of the targeted mRNA through the partial or complete base paring of the guide strand (Figure 1). This result can be obtained by using single stranded RNAs (ssRNAs), which can be directly incorporated into RISC, or double stranded RNAs (dsRNAs), which require cleavage by the cytoplasmic endoribonuclease Dicer prior to be incorporated into RISC (Li and Rana, 2012). Due to their chemical characteristics, synthetic silencing RNAs do not efficiently enter into cells and are highly susceptible to nuclease degradation. To overcome these limitations, silencing RNAs can be complexed with nanoparticles, typically as polymer- or lipid-based formulations (Tatiparti et al., 2017). It is, however, 
noteworthy that nanoparticles can increase the toxicity of the compound or alter pharmacokinetics and biodistribution of the silencing RNAs. Patisiran is the first RNAi-based drug approved by FDA for the treatment of polyneuropathy caused by hereditary transthyretin-mediated amyloidosis (hATTR). It consists of a dsRNA encapsulated in a nanoparticle that allows the active molecule to reach the liver, where it specifically inhibits the hepatic synthesis of transthyretin (Adams et al., 2018). It remains to be clarified whether this strategy can be effective in organs other than liver, where delivery could be more difficult.

Another strategy is to conjugate the silencing RNAs with ligands of the target molecule. An example is the addition of $\mathrm{N}$-acetylgalactosamine (GalNAc) to the RNA, thus enhancing asialoglycoprotein receptor (ASGR)-mediated uptake into liver hepatocytes (Nair et al., 2014). The major limitation of this strategy could be the rate of receptor recycling. GalNAc delivery is actually involved in several clinical and pre-clinical studies with exciting results (Tanowitz et al., 2017).

\section{SMALL INTERFERING RNA-BASED THERAPIES FOR INFLAMMATORY BOWEL DISEASE}

\section{STNM01: Small Interfering RNA Targeting Carbohydrate Sulfotransferase 15}

The late stage of inflammation in IBD is characterized by the fibrotic process, which derives from an altered balance between matrix deposition and degradation (Rieder et al., 2017). Carbohydrate sulfotransferase 15 (CHST15) is a sulfotransferase responsible for biosynthesis of chondroitin sulfate E-type (CS-E), which binds to pro-inflammatory and pro-fibrotic mediators, adhesion molecules, receptor for advanced glycation end-product (RAGE), and pathogenic microorganisms, all of them involved in fibrogenesis. CHST15 is increased in the colon of active CD patients (Belmiro et al., 2005; Suzuki et al., 2016, 2017). STNM01, a synthetic, double-stranded RNA oligonucleotide directed against CHST15, ameliorated acute and chronic DSS induced-colitis and reduced colonic deposition of collagen in mice (Suzuki et al., 2016). A phase 1, randomized, double blind, placebo-controlled, clinical trial evaluated the safety of STNM01 in patients with CD (Suzuki et al., 2017). Eighteen $\mathrm{CD}$ patients with mucosal lesions refractory to conventional therapies received a single-dose, endoscopic, submucosal injection

\section{REFERENCES}

Abraham, C., and Cho, J. H. (2009). Inflammatory bowel disease. N. Engl. J. Med. 361, 2066-2078. doi: 10.1056/NEJMra0804647

Adams, D., Gonzalez-Duarte, A., O'riordan, W. D., Yang, C. C., Ueda, M., Kristen, A. V., et al. (2018). Patisiran, an RNAi therapeutic, for hereditary transthyretin amyloidosis. N. Engl. J. Med. 379, 11-21. doi: 10.1056/ NEJMoa1716153

Andronescu, M., Zhang, Z. C., and Condon, A. (2005). Secondary structure prediction of interacting RNA molecules. J. Mol. Biol. 345, 987-1001. doi: 10.1016/j.jmb.2004.10.082 of 2.5, 25, or $250 \mathrm{nM}$ STNM01 (three patients per group) or placebo (nine patients). The drug was well tolerated, CHST15 expression was reduced 1 month after the injection, and the drug attenuated intestinal inflammation and fibrosis.

\section{CONCLUSION}

The rationale for the use of antisense-based therapies in IBD is supported by the benefit seen in preclinical models and initial clinical studies, together with the safety profiles of the compounds. Unfortunately, however, large clinical trials have not confirmed the promising results obtained with ASOs in preclinical models. Although, it is unclear why these treatments failed in patients, it is conceivable that some factors either related to the target or route of administration may have contributed to these negative results. For example, the negative results of alicaforsen can, in part, rely on the fact that ICAM-1 is just one of the various molecules involved in leukocytes trafficking, and therefore, even in the absence of ICAM-1, other integrins could promote recruitment of activated leukocytes in the gut. Another possibility is that systemic administration of ASO could be not ideal for allowing optimal concentration of the drug within the gut tissue, where there is the main expression of the target. This hypothesis is supported by the demonstration that rectal administration of alicaforsen is of benefit in patients with distal UC and in patients with pouchitis. While STNM01 is the only siRNA currently tested in IBD, there is sufficient evidence to believe that RNAi technology can represent a new and valid approach to regulate the expression of disease-related genes. Some issues in the design and development of these compounds, such as correct identification of target mRNAs, stability, and delivery to the site of interest remain to be solved.

\section{DATA AVAILABILITY}

All datasets generated for this study are included in the manuscript.

\section{AUTHOR CONTRIBUTIONS}

DF and VD wrote the paper. MF, IM and BR contributed to supervise parts of the paper. GM designed and drafted the paper.

Babyatsky, M. W., Rossiter, G., and Podolsky, D. K. (1996). Expression of transforming growth factors alpha and beta in colonic mucosa in inflammatory bowel disease. Gastroenterology 110, 975-984. doi: 10.1053/gast.1996.v110. pm8613031

Belmiro, C. L. R., Souza, H. S. P., Elia, C. C. S., Castelo-Branco, M. T. L., Silva, F. R., Machado, R. L., et al. (2005). Biochemical and immunohistochemical analysis of glycosaminoglycans in inflamed and non-inflamed intestinal mucosa of patients with Crohn's disease. Int. J. Color. Dis. 20, 295-304. doi: 10.1007/s00384-004-0677-2

Benimetskaya, L., Berton, M., Kolbanovsky, A., Benimetsky, S., and Stein, C. A. (1997). Formation of a G-tetrad and higher order structures correlates with 
biological activity of the RelA (NF-kappaB p65) 'antisense' oligodeoxynucleotide. Nucleic Acids Res. 25, 2648-2656. doi: 10.1093/nar/25.13.2648

Bennett, C. F., Baker, B. F., Pham, N., Swayze, E., and Geary, R. S. (2017). Pharmacology of antisense drugs. Annu. Rev. Pharmacol. Toxicol. 57, 81-105. doi: 10.1146/annurev-pharmtox-010716-104846

Bennett, C. F., Kornbrust, D., Henry, S., Stecker, K., Howard, R., Cooper, S., et al. (1997). An ICAM-1 antisense oligonucleotide prevents and reverses dextran sulfate sodium-induced colitis in mice. J. Pharmacol. Exp. Ther. 280, 988-1000.

Boirivant, M., Pallone, F., Di Giacinto, C., Fina, D., Monteleone, I., Marinaro, M., et al. (2006). Inhibition of Smad7 with a specific antisense oligonucleotide facilitates TGF-beta1-mediated suppression of colitis. Gastroenterology 131, 1786-1798. doi: 10.1053/j.gastro.2006.09.016

Burel, S. A., Hart, C. E., Cauntay, P., Hsiao, J., Machemer, T., Katz, M., et al. (2016). Hepatotoxicity of high affinity gapmer antisense oligonucleotides is mediated by RNase $\mathrm{H} 1$ dependent promiscuous reduction of very long premRNA transcripts. Nucleic Acids Res. 44, 2093-2109. doi: 10.1093/nar/gkv1210

Chan, J. H., Lim, S., and Wong, W. S. (2006). Antisense oligonucleotides: from design to therapeutic application. Clin. Exp. Pharmacol. Physiol. 33, 533-540. doi: $10.1111 /$ j. $1440-1681.2006 .04403 . x$

Chery, J. (2016). RNA therapeutics: RNAi and antisense mechanisms and clinical applications. Postdoc J. 4, 35-50.

Crooke, S. T. (2004). Progress in antisense technology. Annu. Rev. Med. 55, 61-95. doi: 10.1146/annurev.med.55.091902.104408

Crooke, S. T. (2017). Molecular mechanisms of antisense oligonucleotides. Nucleic Acid Ther. 27, 70-77. doi: 10.1089/nat.2016.0656

Ding, Y., Chan, C. Y., and Lawrence, C. E. (2004). Sfold web server for statistical folding and rational design of nucleic acids. Nucleic Acids Res. 32, W135-W141. doi: 10.1093/nar/gkh449

Duell, P. B., Santos, R. D., Kirwan, B. A., Witztum, J. L., Tsimikas, S., and Kastelein, J. J. P. (2016). Long-term mipomersen treatment is associated with a reduction in cardiovascular events in patients with familial hypercholesterolemia. J. Clin. Lipidol. 10, 1011-1021. doi: 10.1016/j. jacl.2016.04.013

Eckstein, F. (2014). Phosphorothioates, essential components of therapeutic oligonucleotides. Nucleic Acid Ther. 24, 374-387. doi: 10.1089/nat.2014.0506

Eder, P. S., Devine, R. J., Dagle, J. M., and Walder, J. A. (1991). Substrate specificity and kinetics of degradation of antisense oligonucleotides by a $3^{\prime}$ exonuclease in plasma. Antisense Res. Dev. 1, 141-151. doi: 10.1089/ ard.1991.1.141

Feagan, B. G., Sands, B. E., Rossiter, G., Li, X., Usiskin, K., Zhan, X., et al. (2018). Effects of mongersen (GED-0301) on endoscopic and clinical outcomes in patients with active Crohn's disease. Gastroenterology 154, 61-64.e66. doi: 10.1053/j.gastro.2017.08.035

Gorelik, L., and Flavell, R. A. (2002). Transforming growth factor-beta in T-cell biology. Nat. Rev. Immunol. 2, 46-53. doi: 10.1038/nri704

Goyal, N., and Narayanaswami, P. (2018). Making sense of antisense oligonucleotides: a narrative review. Muscle Nerve 57, 356-370. doi: 10.1002/ mus. 26001

Greuter, T., Biedermann, L., Rogler, G., Sauter, B., and Seibold, F. (2016). Alicaforsen, an antisense inhibitor of ICAM-1, as treatment for chronic refractory pouchitis after proctocolectomy: a case series. United European Gastroenterol. J. 4, 97-104.

Greuter, T., Vavricka, S. R., Biedermann, L., Pilz, J., Borovicka, J., Seibold, F., et al. (2018). Alicaforsen, an antisense inhibitor of intercellular adhesion molecule-1, in the treatment for left-sided ulcerative colitis and ulcerative proctitis. Dig. Dis. 36, 123-129. doi: 10.1159/000484979

Hagedorn, P. H., Persson, R., Funder, E. D., Albaek, N., Diemer, S. L., Hansen, D. J., et al. (2018). Locked nucleic acid: modality, diversity, and drug discovery. Drug Discov. Today 23, 101-114. doi: 10.1016/j.drudis.2017.09.018

Hart, A. L., Ng, S. C., Mann, E., Al-Hassi, H. O., Bernardo, D., and Knight, S. C. (2010). Homing of immune cells: role in homeostasis and intestinal inflammation. Inflamm. Bowel Dis. 16, 1969-1977. doi: 10.1002/ibd.21304

Heldin, C. H., Miyazono, K., and Ten Dijke, P. (1997). TGF-beta signalling from cell membrane to nucleus through SMAD proteins. Nature 390, 465-471. doi: 10.1038/37284

Ho, S. P., Bao, Y., Lesher, T., Malhotra, R., Ma, L. Y., Fluharty, S. J., et al. (1998). Mapping of RNA accessible sites for antisense experiments with oligonucleotide libraries. Nat. Biotechnol. 16, 59-63. doi: 10.1038/nbt0198-59
Izzo, R., Bevivino, G., De Simone, V., Sedda, S., Monteleone, I., Marafini, I., et al. (2018). Knockdown of Smad7 with a specific antisense oligonucleotide attenuates colitis and colitis-driven colonic fibrosis in mice. Inflamm. Bowel Dis. 24, 1213-1224. doi: 10.1093/ibd/izy062

Jabs, D. A., and Griffiths, P. D. (2002). Fomivirsen for the treatment of cytomegalovirus retinitis. Am J. Ophthalmol. 133, 552-556. doi: 10.1016/ S0002-9394(02)01325-9

Khorkova, O., and Wahlestedt, C. (2017). Oligonucleotide therapies for disorders of the nervous system. Nat. Biotechnol. 35, 249-263. doi: 10.1038/nbt.3784

Laudisi, F., Dinallo, V., Di Fusco, D., and Monteleone, G. (2016). Smad7 and its potential as therapeutic target in inflammatory bowel diseases. Curr. Drug Metab. 17, 303-306. doi: 10.2174/1389200217666151210130103

Lawrance, I. C., Wu, F., Leite, A. Z., Willis, J., West, G. A., Fiocchi, C., et al. (2003). A murine model of chronic inflammation-induced intestinal fibrosis down-regulated by antisense NF-kappa B. Gastroenterology 125, 1750-1761. doi: 10.1053 /j.gastro.2003.08.027

Leask, A., and Abraham, D. J. (2004). TGF-beta signaling and the fibrotic response. FASEB J. 18, 816-827. doi: 10.1096/f.03-1273rev

Li, Z., and Rana, T. M. (2012). Molecular mechanisms of RNA-triggered gene silencing machineries. Acc. Chem. Res. 45, 1122-1131. doi: 10.1021/ar200253u

Macdonald, T. T., Monteleone, I., Fantini, M. C., and Monteleone, G. (2011). Regulation of homeostasis and inflammation in the intestine. Gastroenterology 140, 1768-1775. doi: 10.1053/j.gastro.2011.02.047

Miner, P. B. Jr., Wedel, M. K., Xia, S., and Baker, B. F. (2006). Safety and efficacy of two dose formulations of alicaforsen enema compared with mesalazine enema for treatment of mild to moderate left-sided ulcerative colitis: a randomized, double-blind, active-controlled trial. Aliment. Pharmacol. Ther. 23, 1403-1413. doi: 10.1111/j.1365-2036.2006.02837.x

Monteleone, G., Fantini, M. C., Onali, S., Zorzi, F., Sancesario, G., Bernardini, S., et al. (2012). Phase I clinical trial of Smad7 knockdown using antisense oligonucleotide in patients with active Crohn's disease. Mol. Ther. 20, 870-876. doi: 10.1038/mt.2011.290

Monteleone, G., Kumberova, A., Croft, N. M., Mckenzie, C., Steer, H. W., and Macdonald, T. T. (2001). Blocking Smad7 restores TGF-betal signaling in chronic inflammatory bowel disease. J. Clin. Invest. 108, 601-609. doi: 10.1172/ JCI12821

Monteleone, G., Neurath, M. F., Ardizzone, S., Di Sabatino, A., Fantini, M. C., Castiglione, F., et al. (2015). Mongersen, an oral SMAD7 antisense oligonucleotide, and Crohn's disease. N. Engl. J. Med. 372, 1104-1113. doi: 10.1056/NEJMoa1407250

Murano, M., Maemura, K., Hirata, I., Toshina, K., Nishikawa, T., Hamamoto, N., et al. (2000). Therapeutic effect of intracolonically administered nuclear factor kappa B (p65) antisense oligonucleotide on mouse dextran sulphate sodium (DSS)-induced colitis. Clin. Exp. Immunol. 120, 51-58. doi: 10.1046/j. 1365-2249.2000.01183.x

Nair, J. K., Willoughby, J. L., Chan, A., Charisse, K., Alam, M. R., Wang, Q., et al. (2014). Multivalent $\mathrm{N}$-acetylgalactosamine-conjugated siRNA localizes in hepatocytes and elicits robust RNAi-mediated gene silencing. J. Am. Chem. Soc. 136, 16958-16961. doi: 10.1021/ja505986a

Neurath, M. (2017). Current and emerging therapeutic targets for IBD. Nat. Rev. Gastroenterol. Hepatol. 14:688. doi: 10.1038/nrgastro.2017.138

Neurath, M. F., Fuss, I., Schurmann, G., Pettersson, S., Arnold, K., Muller-Lobeck, H., et al. (1998). Cytokine gene transcription by NF-kappa B family members in patients with inflammatory bowel disease. Ann. N. Y. Acad. Sci. 859, 149-159. doi: 10.1111/j.1749-6632.1998.tb11119.x

Neurath, M. F., Pettersson, S., Meyer Zum Buschenfelde, K. H., and Strober, W. (1996). Local administration of antisense phosphorothioate oligonucleotides to the p65 subunit of NF-kappa B abrogates established experimental colitis in mice. Nat. Med. 2, 998-1004. doi: 10.1038/nm0996-998

Prakash, T. P. (2011). An overview of sugar-modified oligonucleotides for antisense therapeutics. Chem. Biodivers. 8, 1616-1641. doi: 10.1002/ cbdv.201100081

Rieder, F., Fiocchi, C., and Rogler, G. (2017). Mechanisms, management, and treatment of fibrosis in patients with inflammatory bowel diseases. Gastroenterology 152, 340-350.e346. doi: 10.1053/j.gastro.2016.09.047

Rogler, G., Brand, K., Vogl, D., Page, S., Hofmeister, R., Andus, T., et al. (1998). Nuclear factor kappaB is activated in macrophages and epithelial cells of inflamed intestinal mucosa. Gastroenterology 115, 357-369. doi: 10.1016/S0016-5085(98)70202-1 
Schreiber, S., Nikolaus, S., and Hampe, J. (1998). Activation of nuclear factor kappa B inflammatory bowel disease. Gut 42, 477-484. doi: 10.1136/gut.42.4.477

Schreiber, S., Nikolaus, S., Malchow, H., Kruis, W., Lochs, H., Raedler, A., et al. (2001). Absence of efficacy of subcutaneous antisense ICAM-1 treatment of chronic active Crohn's disease. Gastroenterology 120, 1339-1346. doi: 10.1053/gast.2001.24015

Sedda, S., Marafini, I., Dinallo, V., Di Fusco, D., and Monteleone, G. (2015). The TGF-beta/Smad system in IBD pathogenesis. Inflamm. Bowel Dis. 21, 2921-2925. doi: 10.1097/MIB.0000000000000542

Sen, D., and Gilbert, W. (1992). Novel DNA superstructures formed by telomerelike oligomers. Biochemistry 31, 65-70.

Sharma, V. K., and Watts, J. K. (2015). Oligonucleotide therapeutics: chemistry, delivery and clinical progress. Future Med. Chem. 7, 2221-2242. doi: 10.4155/ fmc. 15.144

Shi, Y., and Massague, J. (2003). Mechanisms of TGF-beta signaling from cell membrane to the nucleus. Cell 113, 685-700. doi: 10.1016/ S0092-8674(03)00432-X

Stein, C. A. (2001). The experimental use of antisense oligonucleotides: a guide for the perplexed. J. Clin. Invest. 108, 641-644. doi: 10.1172/JCI13885

Suzuki, K., Arumugam, S., Yokoyama, J., Kawauchi, Y., Honda, Y., Sato, H., et al. (2016). Pivotal role of carbohydrate sulfotransferase 15 in fibrosis and mucosal healing in mouse colitis. PLoS One 11:e0158967. doi: 10.1371/ journal.pone.0158967

Suzuki, K., Yokoyama, J., Kawauchi, Y., Honda, Y., Sato, H., Aoyagi, Y., et al. (2017). Phase 1 clinical study of siRNA targeting carbohydrate sulphotransferase 15 in Crohn's disease patients with active mucosal lesions. J. Crohns Colitis 11, 221-228.

Tanowitz, M., Hettrick, L., Revenko, A., Kinberger, G. A., Prakash, T. P., and Seth, P. P. (2017). Asialoglycoprotein receptor 1 mediates productive uptake of $\mathrm{N}$-acetylgalactosamine-conjugated and unconjugated phosphorothioate antisense oligonucleotides into liver hepatocytes. Nucleic Acids Res. 45, 12388-12400. doi: 10.1093/nar/gkx960

Tatiparti, K., Sau, S., Kashaw, S. K., and Iyer, A. K. (2017). siRNA delivery strategies: a comprehensive review of recent developments. Nanomaterials 7:77. doi: 10.3390/nano7040077

Tu, G. C., Cao, Q. N., Zhou, F., and Israel, Y. (1998). Tetranucleotide GGGA motif in primary RNA transcripts. Novel target site for antisense design. J. Biol. Chem. 273, 25125-25131. doi: 10.1074/jbc.273.39.25125

Vainer, B., and Nielsen, O. H. (2000). Changed colonic profile of P-selectin, platelet-endothelial cell adhesion molecule-1 (PECAM-1), intercellular adhesion molecule-1 (ICAM-1), ICAM-2, and ICAM-3 in inflammatory bowel disease. Clin. Exp. Immunol. 121, 242-247. doi: 10.1046/j.1365-2249.2000.01296.x

Vallance, B. A., Gunawan, M. I., Hewlett, B., Bercik, P., Van Kampen, C., Galeazzi, F., et al. (2005). TGF-betal gene transfer to the mouse colon leads to intestinal fibrosis. Am. J. Physiol. Gastrointest. Liver Physiol. 289, G116-G128. doi: 10.1152/ajpgi.00051.2005
Van Deventer, S. J., Wedel, M. K., Baker, B. F., Xia, S., Chuang, E., and Miner, P. B. Jr. (2006). A phase II dose ranging, double-blind, placebocontrolled study of alicaforsen enema in subjects with acute exacerbation of mild to moderate left-sided ulcerative colitis. Aliment. Pharmacol. Ther. 23, 1415-1425. doi: 10.1111/j.1365-2036.2006.02910.x

Vickers, T. A., Wyatt, J. R., and Freier, S. M. (2000). Effects of RNA secondary structure on cellular antisense activity. Nucleic Acids Res. 28, 1340-1347. doi: $10.1093 /$ nar/28.6.1340

Wahlestedt, C., Salmi, P., Good, L., Kela, J., Johnsson, T., Hokfelt, T., et al. (2000). Potent and nontoxic antisense oligonucleotides containing locked nucleic acids. Proc. Natl. Acad. Sci. USA 97, 5633-5638.

Yacyshyn, B. R., Bowen-Yacyshyn, M. B., Jewell, L., Tami, J. A., Bennett, C. F., Kisner, D. L., et al. (1998). A placebo-controlled trial of ICAM-1 antisense oligonucleotide in the treatment of Crohn's disease. Gastroenterology 114, 1133-1142. doi: 10.1016/S0016-5085(98)70418-4

Yacyshyn, B., Chey, W. Y., Wedel, M. K., Yu, R. Z., Paul, D., and Chuang, E. (2007). A randomized, double-masked, placebo-controlled study of alicaforsen, an antisense inhibitor of intercellular adhesion molecule 1, for the treatment of subjects with active Crohn's disease. Clin. Gastroenterol. Hepatol. 5, 215-220. doi: 10.1016/j.cgh.2006.11.001

Yacyshyn, B. R., Chey, W. Y., Goff, J., Salzberg, B., Baerg, R., Buchman, A. L., et al. (2002). Double blind, placebo controlled trial of the remission inducing and steroid sparing properties of an ICAM-1 antisense oligodeoxynucleotide, alicaforsen (ISIS 2302), in active steroid dependent Crohn's disease. Gut 51, 30-36. doi: 10.1136/gut.51.1.30

Zorzi, F., Calabrese, E., Monteleone, I., Fantini, M., Onali, S., Biancone, L., et al. (2012). A phase 1 open-label trial shows that smad7 antisense oligonucleotide (GED0301) does not increase the risk of small bowel strictures in Crohn's disease. Aliment. Pharmacol. Ther. 36, 850-857. doi: 10.1111/apt.12051

Zuker, M. (2003). Mfold web server for nucleic acid folding and hybridization prediction. Nucleic Acids Res. 31, 3406-3415. doi: 10.1093/nar/gkg595

Conflict of Interest Statement: GM has filed a patent related to the treatment of IBD with Smad7 antisense oligonucleotides.

The remaining authors declare that the research was conducted in the absence of any commercial or financial relationships that could be construed as a potential conflict of interest.

Copyright (c) 2019 Di Fusco, Dinallo, Marafini, Figliuzzi, Romano and Monteleone. This is an open-access article distributed under the terms of the Creative Commons Attribution License (CC BY). The use, distribution or reproduction in other forums is permitted, provided the original author(s) and the copyright owner(s) are credited and that the original publication in this journal is cited, in accordance with accepted academic practice. No use, distribution or reproduction is permitted which does not comply with these terms. 